\title{
The Trade Structure of Chinese Manufactured Exports: 1999-2009
}

\author{
${ }^{1}$ Hao Wei and ${ }^{2}$ Xi Wang \\ ${ }^{1}$ School of Economics and Business Administration, Beijing Normal University, China \\ ${ }^{2}$ School of International Business, Beijing Language and Culture University, China
}

\begin{abstract}
Based on the classification of 144 kinds of manufactured products, we make an analysis on the technological structure of Chinese manufactured exports from 1999-2009. We find that: (1) the trade structure of Chinese manufactured exports are totally changed in both world and US markets, the share of Low Technology (LT) products in the total exports shrank while the share of High Technology (HT) products expanded. The development of HT1 products (electronic and electrical products) contributed a lot to the rapid growth of the share of HT exports. (2) Compared with other BRICs and select Asian countries, China had absolute advantage in the US import market. However, in contrast to Canada, Mexico, Japan and Germany, China has no revealed comparative advantage except in LT and HT1 products. (3) The trade structure for Chinese exports manifests the tendency of optimization, the best example is Medium Technology (MT) products and the least is HT products.
\end{abstract}

Keywords: Export, Manufactures, China, Trade Structure, Low Technology (LT), Medium Technology (MT), Comparative Advantage

\section{INTRODUCTION}

Over the past three decades, exports have always been the significant engine for the rapid growth of the Chinese economy. However, the decrease of the overseas market demand, as a result of the economic crisis initiated by the USA subprime crisis, brings about an unprecedented challenge towards Chinese exports. The economic crisis carried in by investment, trade, information and so forth brings a gradual blow to China's real economy. The Chinese economy faces the risk which is worse than expected, so the falling growth rate, especially the falling exports, becomes a question of questions, bringing massive and severe challenges to the Chinese economy. The Chinese Ministry of Commerce has directly stated that stabilizing overseas market demand and assuring exports are still their first priority. Under the economic crisis, facing the fierce competition in the world market and the change of overseas demand structure, the trade structure of exports is one of the main factors influencing Chinese export volume.

Based on all of the above, this study will make a deep analysis on the trade structure of Chinese manufactures over the period 1999-2009, in both the world and US market. Furthermore, comparisons will be made between China, Russia, India, Brazil, Germany, Canada, Mexico, Japan, South Korea, Thailand and Malaysia concerning their share of different categories of export products in the US market. With a fuller understanding of the trade structure of Chinese export manufactures, this study puts forward some reasonable suggestions for the sustainable development of Chinese trade.

\subsection{Literature Review}

Manufactures trade is both very significant and complicated. It is the mix of several competitive edges that are closely related to trade policies. Because manufactured products are more complex than primary commodities, the technology level and added value of a country's manufactured products embody the competitive level of the country's manufacturing sector. Scholars at home and abroad have numerous empirical studies on the manufacturing comparative advantage and trade structure from different angles.

Key researchers Bender and Li (2001) analyzed how RCA index and export structure of East Asian countries'

Corresponding Author: Hao Wei, School of Economics and Business Administration, Beijing Normal University, China 
manufacture products differ from those of Latin America. It concentrated on three categories of manufacture's share in the world market and their trade pattern improvement during 1981-1997, especially on the RCA correlations and variation scope. Lall (2002) made a comparative analysis of the influence that different categories of Chinese manufactured exports have in East Asian newly industrializing countries and Latin American developing countries classified by technology in 1985 and 1998 . Kwan (2002) provided an empirical test of complimentary and competitive bilateral trade between China and Japan by the Export Sophistication Index. Moreover, it extends an overall comparison of the HT manufactures comparative advantage and competitiveness in Asian countries, fully manifesting the Asian Flying Goose Model, in 1990 and 2000. Hao et al. (2005) applied an analysis of Chinese manufactures comparative advantage and trade pattern over 1997-2002. Gang et al. (2006) provided a method of analyzing trade pattern based on the technological distribution of traded goods, which analyzed the China's trade structure in 1995 and 2003. Chen (2006) divided export products into resource-intensive, capital-intensive and labor-intensive products and calculated the trade structure over 1980-2000.

Lall (2002) indicated that human resources, technologic achievements, FDI and technology imports are the internal drives of improving the manufacture's competitiveness. Schott (2008) gauges the relative sophistication of Chinese exports, finding that China's export overlap with the OECD is much greater than one would predict given its low wages, the prices that US consumers are willing to pay for China's exports are substantially lower than the prices they are willing to pay for OECD exports. Cui and Syed (2007) finds that China is moving away from traditional assembly operations in its processing activities and its exports have started to rely more on domestically sourced components.

In summary, research has been done largely on the trade structure of Chinese manufactures export over 1980-2000 while rarely any study focused after the 21 st century. Entering the 21 st century in terms of accession to the WTO, China has stepped into the export booming stage. In 1999 China was the ninth largest exporting country in the world, in 2001 the sixth, in 2007 China left America behind and in 2009 China surpassed Germany becoming the largest exporting country in the world. With the rapid growth of export volume since 1999, how is the export structure of Chinese manufacturing? Have qualitative changes happened? To answer these question, based on the categorization of 144 kinds of manufacturing (at the 3-digit SITC level),we research on the trade structure of Chinese manufacture exports in different technological level, in both US and world markets, over 1999-2009.

\subsection{Evaluation Index System and Data}

\subsubsection{Index to Evaluate Trade Structure} follows.

Many trade structure indexes are calculated as

Trade structure index of Chinese manufactures to the world:

$$
\text { trade structure }=\frac{\text { Chinese export of commodity } i}{\text { Chinese export of all commodities }} \times 100 \%
$$

Trade structure index of Chinese manufactures to the US:

trade structure $=\frac{\text { Chinese export to USA of commodity i }}{\text { Chinese export to USA of all commodities }} \times 100 \%$

Trade structure index of different categories of Chinese manufactures in the US market:

trade structure $=\frac{\text { Chinese export to USA of commodity } i}{\text { USA import of all commodities } i} \times 100 \%$

Trade structure index of all countries' different categories of manufactures in the US market:

trade structure $=\frac{\text { country } \mathrm{j} \text { export to USA of commodity } \mathrm{i}}{\text { USA import of all commodities } \mathrm{i}} \times 100 \%$

\subsection{Trade Structural Change Index}

There are two indexes measuring the trade structural change, the Lawrence Index and the Beneficiary Index.

\subsection{Structural Change Index: Lawrence Index}

The Lawrence Index varies from zero to one. When it is close to one, it indicates that a country's trade pattern changes more and when it is close to zero, there is less obvious change. The Lawrence Index (Bender and $\mathrm{Li}, 2001$ ) is expressed as follows:

$$
\mathrm{L}=(1 / 2) \sum_{\mathrm{i}=1}^{\mathrm{n}}\left|\mathrm{S}_{\mathrm{i}, \mathrm{t}}-\mathrm{S}_{\mathrm{i}, \mathrm{t}-1}\right|
$$

where, $S_{i, t}$ in $S_{i, t}=x_{i, t} / \sum_{i} x_{i, t}$ Measures the share of commodity i in a country's total exports in the year $\mathrm{t}$. 


\subsection{Structural Optimization Index: Beneficiary Index}

The beneficiary index (Bender and Li, 2001), which is also called the Structural Optimization Index, reflects whether a country's export pattern changes corresponding with the world dynamic demand. That is to say it measures the optimization scope of a country's trade pattern. If the figure is positive, it indicates that the export pattern tends to be optimized. The bigger the figure is, the more obviously the trade structure is optimized. The Beneficiary Index is expressed as follows:

$$
\text { BSCI }=\sum_{i=1}^{n}\left[\left[\frac{\mathrm{x}_{\mathrm{i}, \mathrm{t}} / \sum_{\mathrm{i}} \mathrm{x}_{\mathrm{i}, \mathrm{t}}}{\mathrm{x}_{\mathrm{i}, \mathrm{t}-1} / \sum_{\mathrm{i}} \mathrm{x}_{\mathrm{i}, \mathrm{t}}}-1\right] *\left[\frac{\left(\mathrm{m}_{\mathrm{i}, \mathrm{t}} / \mathrm{m}_{\mathrm{i}, \mathrm{t}-\mathrm{1}}\right)^{\text {"world" }}}{\operatorname{Average}\left(\mathrm{m}_{\mathrm{i}, \mathrm{t}} / \mathrm{m}_{\mathrm{i}, \mathrm{t}-1}\right)}-1\right] *\left(\frac{\mathrm{x}_{\mathrm{i}, \mathrm{t}}}{\sum_{\mathrm{i}} \mathrm{x}_{\mathrm{i}, \mathrm{t}}}\right)\right]
$$

where, $x_{i, t}$ is a country's export of commodity $i$ in the year $t$, it $m_{i, t}$ is world's export of commodity $i$ in the year $t$.

\subsection{Data}

This study focuses on the changes of the trade structure of Chinese manufactured exports over 1999-2009. All data comes from the UN Comtrade database (SITC 3digit, revision 3 ).

\subsection{Scope and Categorization of Manufactured Products}

Based on the categorization Sanjaya Lall used to analyze the competitiveness of developing countries' manufactured products, this study classifies 144 kinds of manufacturing (on SITC Rev. 3 data) by technology into five general groups and nine small groups specifically, which cover the majority of Chinese manufactured exports. Table 1 is a detailed expression of Sanjaya Lall's method of categorizing manufactured products.

\subsection{Resource Based (RB) Products}

Resource Based (RB) products tend to be simple and labor-intensive, but there are segments using capital-, scaleand skill-intensive technologies (e.g., petroleum refining or modern processed foods). Competitive advantages in these products arise generally from local availability of natural resources. We draw a distinction between RB1, agriculturebased products and RB2, others. There are 7 types of RB1 products and 16 types of RB2 products in our discussion.

\subsection{Low Technology (LT) Products}

Low Technology (LT) products tend to have stable, well-diffused technologies. These technologies are primarily embodied in the capital equipment; the low end of the range has relatively simple skill requirements. Many traded products are undifferentiated and compete on price: thus, labor costs tend to be the major element of cost in competitiveness. We should note that products of major interest to developing countries tend to be in the lower quality segments and are really based on simple technologies and price rather than quality competition. We distinguish between LT1, textiles, garments, footwear and the LT2, other low technology products. There are 20 types of LT1 products and 24 types of LT2 products in our discussion. LT1 products have undergone massive relocation from rich to poor countries, with assembly operations shifting to low wage sites and complex design and manufacturing functions retained in developed countries. This relocation has been the engine of export growth in this industry.

\subsection{Medium Technology (MT) Products}

Medium Technology (MT) products, comprising the bulk of skill- and scale-intensive technologies in capital goods and intermediate products, are the center of industrial activity in mature economies. They tend to have complex technologies, with moderately high levels of $\mathrm{R}$ and $\mathrm{D}$, advanced skill needs and lengthy learning periods. We divide them into three sub-groups. MT1, automotive products, are of particular export interest to newly industrializing countries, particularly in East Asia and Latin America. MT2, process industries, mainly chemicals and basic metals, are different in their technological features from MT3, engineering products. There are 5 types of MT1 products, 17 types of MT2 products and 30 types of MT3 products in our discussion.

\subsection{High Technology (HT) Products}

High Technology (HT) products have advanced and rapidly-changing technologies, with high R\&D investments and prime emphasis on product design. The most advanced technologies require sophisticated technology infrastructures, high levels of specialized technical skills and close interactions between firms, as well as between firms and universities or research institutions. However, some products, like electronics, involve labor-intensive final assembly and their high value-to-weight ratios make it economical to place this stage in low wage areas. These products lead in new international integrated production systems in which different processes are separated and located by MNCs according to fine differences in production costs. We separate HT1, electronic and electrical products, from HT2, other high-tech products. There are 11 types of HT1 products and 7 types of HT2 products in our discussion. 
Table 1. Technological classification of exports

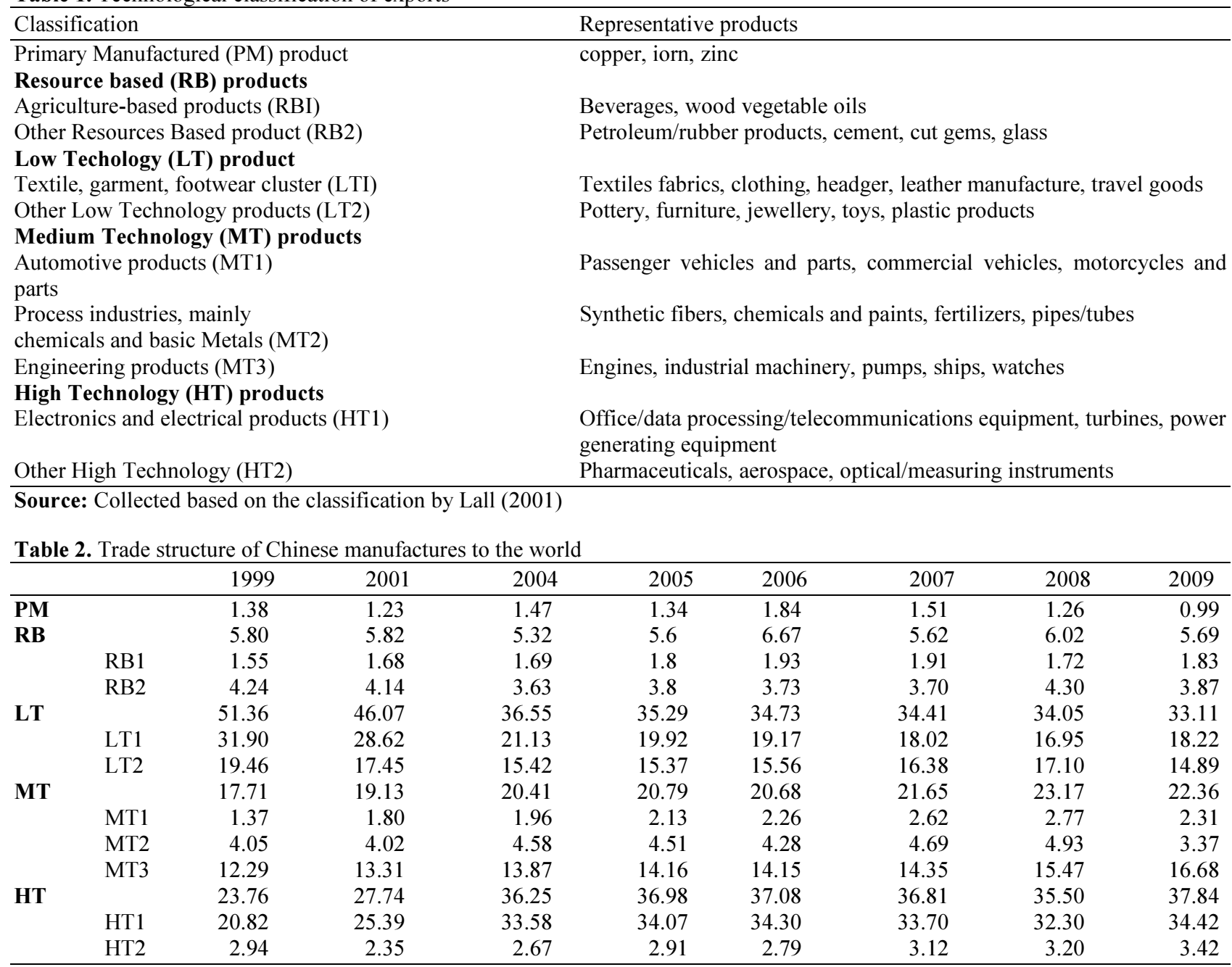

Source: Figures are calculated using the data provided by the UN Comtrade database

\subsection{Analysis on the Export Structure of Chinese Manufacturing}

\subsubsection{Export Structure of Chinese Manufactures to the World}

Table 2 demonstrates the export structure of Chinese manufactures to the world by technology over 1999-2009 specifically.

The share of PM products maintains the tendency of declining, from $1.38 \%$ in $1999-0.99 \%$ in 2009.

The share of RB products generally fluctuates around $5.6 \%$ with little change, in which the share of RB1 products rises increasingly before 2007 , from 1.55 $1.91 \%$ and then decreases slightly in 2008 and 2009; the share of RB2 products continues to drop except in 2008, from $4.24 \%$ in $1999-3.87 \%$ in 2009 .

The share of LT products fell from $51.36 \%$ in 1999 $33.11 \%$ in 2009 , the share of LT1 products (textile, garment and footwear cluster and so on) decline drastically from $31.9 \%$ in $1999-18.22 \%$ in 2009 , nearly 14 percentage points. The share of the other Low Technology (LT2) products goes down from 19.46-14.89\%.

The share of MT products in total exports climb year to year, from $17.71 \%$ in $1999-22.36 \%$ in 2009 . The share of automotive products (MT1) goes up from 1.37-2.31\%. The share of process industries (MT2) tends to rise before 2008, from $4.05-4.93 \%$, but fall rapidly to $3.37 \%$. The share of engineering products (MT3) continues to move up, from 12.29 in $1999-16.68 \%$ in 2009. 
The share of HT products in total exports has a strong ascent, from $23.76 \%$ in $1999-37.84 \%$ in 2009. The export share of High Technology (HT) products surpasses that of LT products in 2005, becoming the top export commodity. In detail, the share of electronic and electrical products (HT1) goes up from 20.82-34.42\% and the share of other high-tech products (HT2) tends to ascend, from 2.94-3.42\%. Over the period 1999-2009, the trade structure of Chinese exports to the world causes qualitative change, which is characterized as the decline in share of LT products, the ascending share of HT products and the slight rise in share of MT products. In 1999, LT products occupy almost $50 \%$ of the total export, becoming the top export commodity. In 2005, HT products exceeded LT products to become the top export commodity and remains so now.

\subsection{Trade Structure of Chinese Manufactures to the US}

Table 3 demonstrates the export structure of Chinese manufactures to the US by technology over 1999-2009 specifically.

The share of PM products increased from $0.37-0.76 \%$.

The share of RB products in total export generally continued to climb through 2008, from $3.5-5.08 \%$, but fell to $4.5 \%$ in 2009 . The share of RB1 products rose from $1.35-2.22 \%$ while the share of RB2 products had no obvious change.

The share of LT products fell from $55.98 \%$ in 1999 $38.55 \%$ in 2009 , among which the share of LT1 products didn't change very large. In 1999 the share of LT1 is about $20 \%$, then maintains at $16 \%$ over 2004-08, recovering to $18.3 \%$ in 2009 . The share of LT2 products decreased from $35.14 \%$ in $1999-20.24 \%$ in 2009 , nearly a 15 percentage point drop.
The share of MT products in total exports fluctuated between 16 and 19.5\%, in which MT1 and MT2 products had a very small share. The share of MT1 went up from $1.2-2.2 \%$. MT2 products rose from 0.99 in $1999-4.54 \%$ in 2006 , but fall rapidly to $1.97 \%$ in 2009 . MT3 products, which occupied the highest share, continued to fall slightly, from roughly $14 \%$ in 1999 -about $12 \%$ in 2009 .

The share of HT products in total exports had a strong ascent, from 23.77 in $1999-39.38 \%$ in 2009 , by nearly 16 percentage points. The share of HT1 went up from 21.47$36.97 \%$ while HT2 exports had no obvious change.

In summary, over 1999-2009 the trade structure of Chinese exports to the US caused qualitative change as well. This is characterized as the decline in share of LT products and the ascent in share of HT products, which became the top export commodity in 2007 and 2009 . These shifts in US market are almost the same changes as those in world market. The difference is that the share of MT products in world market has grown, while the share of MT products in US market has had a tendency to decline.

\subsection{Share of Chinese Manufactured Export in US Imports}

Table 4 gives the share for Chinese manufactured exports by technology in the total import volume of the US over 2004-09 specifically.

The share of PM products in the US market increased from $1.63-6.75 \%$.

The share of RB products tended to climb from 10.04$22.33 \%$, in which the share of RB1 and RB2 products both had a tendency to rise, where the former one is more obvious, from $6.92 \%$ in $2004-15.79 \%$ in 2009 .

Table 3. Trade structure of Chinese manufactures to the US

\begin{tabular}{|c|c|c|c|c|c|c|c|c|c|}
\hline & & 1999 & 2001 & 2004 & 2005 & 2006 & 2007 & 2008 & 2009 \\
\hline $\mathbf{P M}$ & & 0.37 & 0.21 & 0.31 & 0.52 & 0.78 & 0.61 & 0.58 & 0.76 \\
\hline \multirow[t]{3}{*}{ RB } & & 3.50 & 3.54 & 4.06 & 4.35 & 4.74 & 4.63 & 5.08 & 4.50 \\
\hline & RB1 & 1.35 & 1.38 & 2.21 & 2.31 & 2.57 & 2.51 & 2.25 & 2.22 \\
\hline & RB2 & 2.14 & 2.17 & 1.84 & 2.04 & 2.17 & 2.12 & 2.83 & 2.28 \\
\hline \multirow[t]{3}{*}{$\mathbf{L T}$} & & 55.98 & 56.28 & 39.89 & 39.93 & 38.23 & 38.44 & 37.94 & 38.55 \\
\hline & LT1 & 20.83 & 23.59 & 16.10 & 17.89 & 16.67 & 16.42 & 16.08 & 18.30 \\
\hline & LT2 & 35.14 & 32.70 & 23.78 & 22.03 & 21.57 & 22.02 & 21.85 & 20.24 \\
\hline \multirow[t]{4}{*}{ MT } & & 16.39 & 16.77 & 19.92 & 19.22 & 18.61 & 17.75 & 19.39 & 16.81 \\
\hline & MT1 & 1.20 & 1.36 & 2.69 & 2.56 & 2.53 & 2.63 & 2.54 & 2.20 \\
\hline & MT2 & 0.99 & 1.15 & 3.60 & 3.62 & 3.54 & 3.57 & 4.54 & 1.97 \\
\hline & MT3 & 14.20 & 14.26 & 13.63 & 13.04 & 12.54 & 11.55 & 12.31 & 12.64 \\
\hline \multirow[t]{3}{*}{ HT } & & 23.77 & 23.19 & 35.82 & 35.99 & 37.63 & 38.57 & 37.01 & 39.38 \\
\hline & HT1 & 21.47 & 21.13 & 34.06 & 34.41 & 36.01 & 36.59 & 34.75 & 36.97 \\
\hline & HT2 & 2.30 & 2.05 & 1.76 & 1.57 & 1.62 & 1.98 & 2.26 & 2.41 \\
\hline
\end{tabular}

Source: Figures are calculated using the data provided by the UN Comtrade database 
Table 4. Share of Chinese manufactured export in the us market (\%)

\begin{tabular}{|c|c|c|c|c|c|c|c|}
\hline & & 2004 & 2005 & 2006 & 2007 & 2008 & 2009 \\
\hline $\mathbf{P M}$ & & 1.63 & 2.81 & 0.31 & 3.02 & 3.37 & 6.75 \\
\hline \multirow[t]{3}{*}{ RB } & & 10.04 & 12.75 & 16.63 & 19.25 & 21.31 & 22.33 \\
\hline & RB1 & 6.92 & 8.71 & 11.67 & 13.86 & 14.02 & 15.79 \\
\hline & RB2 & 3.12 & 4.04 & 4.95 & 5.39 & 7.29 & 6.54 \\
\hline \multirow[t]{3}{*}{ LT } & & 35.88 & 42.34 & 47.21 & 51.85 & 55.34 & 60.53 \\
\hline & LT1 & 17.51 & 21.62 & 23.98 & 26.31 & 28.02 & 31.76 \\
\hline & LT2 & 18.37 & 20.71 & 23.23 & 25.54 & 27.32 & 28.78 \\
\hline \multirow[t]{4}{*}{ MT } & & 19.93 & 22.93 & 25.30 & 26.62 & 29.98 & 28.08 \\
\hline & MT1 & 1.67 & 1.99 & 2.28 & 2.72 & 3.11 & 3.56 \\
\hline & MT2 & 8.92 & 10.52 & 11.51 & 12.38 & 13.56 & 8.86 \\
\hline & MT3 & 9.34 & 10.42 & 11.51 & 11.52 & 13.32 & 15.66 \\
\hline \multirow[t]{3}{*}{ HT } & & 20.66 & 25.50 & 30.16 & 33.77 & 35.12 & 37.59 \\
\hline & HT1 & 17.37 & 20.71 & 24.51 & 27.01 & 27.20 & 28.67 \\
\hline & HT2 & 3.29 & 4.79 & 5.65 & 6.76 & 7.93 & 8.92 \\
\hline
\end{tabular}

Source: Figures are calculated using the data provided by UN Comtrade database

The share of LT products in the US market grew very quickly, nearly 25 percentage points, from 35.88 $60.53 \%$. The share of LT 1 products rose from $17.51 \%$ in $2004-31.76 \%$ in 2009 and the share of LT2 products increased from $18.37-28.78 \%$.

The share of MT products in the US import market rose as well, from $19.93-28.08 \%$, in which MT1 products occupied the smallest gain, rising from $1.67 \%$ in $2004-$ $3.56 \%$ in 2009 , the share of MT2 products increased from $8.92 \%$ in 2004 to $13.56 \%$ in 2008 , falling rapidly to $8.86 \%$ in 2009 , MT3 products occupied the greatest share of the US market, growing from $9.34 \%$ in 1999 $15.66 \%$ in 2009 .

The share of HT products has had obvious variation in the US import market, ascending from 20.66-37.59\% over 1999-2009, by nearly 17 percentage points. In particular, the share of HT1 increased from $17.37 \%$ in 2004 to $28.67 \%$ in 2009 , by up to $11 \%$ points. The share of HT2 climbed up from 3.29-8.92\%.

In summary, the share of Chinese LT products in the US import market has had extraordinarily conspicuous growth with an obvious increasing tendency in RB1, MT3 and HT1 products.

\subsection{Chinese Share in the US Import Market Compared with Other Countries}

\subsubsection{Compared with Other BRIC Countries}

Table 5 demonstrates the Chinese share of manufactured exports by technology in the US Import Market Compared with Other BRIC countries in 2008. In contrast to three other BRIC countries, apart from PM products, all the other Chinese manufactures exports have absolute advantage in the US import market, far above the total share of the other three countries specifically.
Table 5. Chinese Share of the US Import Market Compared with Other BRIC Countries in 2008

\begin{tabular}{llclll}
\hline & 2008 & China & Russia & India & Brazil \\
\hline PM & & 3.37 & 5.22 & 0.14 & 1.01 \\
RB & & 21.31 & 1.22 & 5.49 & 4.34 \\
& RB1 & 14.02 & 0.28 & 5.05 & 1.78 \\
& RB2 & 7.29 & 0.95 & 5.26 & 1.49 \\
LT & & 55.34 & 0.25 & 5.26 & 1.49 \\
& LT1 & 28.02 & 0.01 & 3.62 & 0.83 \\
& LT2 & 27.32 & 0.24 & 1.64 & 0.66 \\
MT & & 29.98 & 3.01 & 3.15 & 6.83 \\
& MT1 & 3.11 & 0.01 & 0.21 & 0.33 \\
& MT2 & 13.56 & 2.96 & 2.41 & 5.15 \\
HT & MT3 & 13.32 & 0.04 & 0.52 & 1.35 \\
& & 35.12 & 0.08 & 0.97 & 4.30 \\
& HT1 & 27.2 & 0.02 & 0.31 & 0.43 \\
& HT2 & 7.93 & 0.06 & 0.66 & 3.87 \\
\hline
\end{tabular}

Source: Figures are calculated using the data provided by the UN Comtrade database

Russia's share of PM products in the US import market was $5.22 \%$ which was the highest in the four countries in 2008 . China's share was $3.37 \%$ which was higher than India and Brazil. India's share was the lowest at $0.14 \%$.

Chinese share of RB, LT, MT and HT products have the obvious advantages. The share of Chinese products in the US import market was the highest, even higher than the total shares of other three countries combined.

In detail, the share of Chinese RB products was $14.02 \%$, while the share of Russia was the lowest. The share of Chinese LT products was $55.34 \%$, India was $5.26 \%$ and Russia was $0.25 \%$, which was the lowest of the four countries. The share of Chinese MT products was $29.98 \%$, Brazil was $6.83 \%$ and Russia's share was $3.01 \%$, which was the lowest of the four countries. The 
share of Chinese HT products was $35.12 \%$, Brazil's share was $4.3 \%$ and Russia was again the lowest among the four countries at only $0.08 \%$.

\subsection{Compared with Canada, Mexico, Japan and Germany}

Table 6 demonstrates the Chinese share of manufactured exports by technology in the US Import Market compared with the top four US import countries in 2008. Compared with Canada, Mexico, Japan and Germany, the only overwhelming advantage that China has was in LT and HT1 products and the remaining are of no obvious advantage specifically.

PM products and RB products. Canada had the absolute advantage in PM and RB products. Canada's share of PM products in the US import market was $37.01 \%$, which not only was the highest, but higher the other four countries combined. Japan's share was the lowest at $1.3 \%$. Canada's share of RB1 products in the US import market was $36.3 \%$, which was the highest. China's share was $14.02 \%$. The share of the other three countries was less than $7 \%$ and the share of Mexico was $3.69 \%$, the lowest. Every country's share of RB2 products was less than $10 \%$. Canada's share was $8.58 \%$ and the highest. Mexico's share was $2.85 \%$ and the lowest.

LT products and HT1 products. China had the overwhelming advantage in LT and HT1 products. The share of Chinese LT1 products was $28.02 \%$, which was higher than the four other countries combined. Mexico's share was $5.13 \%$, the second highest and the share of Japan was $0.41 \%$, which was the lowest of the five countries. The share of Chinese LT2 products was $27.32 \%$, Canada was $11.72 \%$ and the second highest and Germany was at 3.08\%, making it the lowest among the five countries. The share of Chinese HT2 products was $27.2 \%$, Mexico was $19.31 \%$ and the second highest and the share of Germany was 3\%, which was the lowest in the five countries.

MT products and HT2 products. The share of Japan's MT1 products was the highest at $26.75 \%$. Canada's share was $24.48 \%$ and the second highest and China was at $3.11 \%$ which is the lowest of the five countries. The share of Canada's MT2 products was $19.07 \%$ and the highest, China was the second highest at $13.56 \%$ and Germany was $5.46 \%$ which was the lowest in the five countries. The share of Mexico's MT3 products was $17.75 \%$, the highest. China's share was $13.32 \%$ and the second highest and Germany was $10.66 \%$ which was the lowest. The share of Germany's HT2 products was $16.15 \%$ making it the highest. Canada's share was $13.77 \%$, the second highest and the share of Mexico was only $5.86 \%$, making it the lowest among the five countries.

\subsection{Compared with Korea, Thailand, Malaysia and Japan}

Table 7 demonstrates China's share of manufactured exports by technology in the US Import Market compared with other Asian countries in 2008. In the comparison with Korea, Thailand, Malaysia and Japan, with the exception of MT1 and HT2 products, China had conspicuous advantages in all the other products. Moreover, as to HT2 products, the overall advantage of Korea exceeds Thailand and Malaysia in the US market. Specifically, the share of Japan's MT1 products was the highest at $26.75 \%$. Korea's share was $5.13 \%$, the second highest and the share of Malaysia was $0.02 \%$, which was the lowest among the five countries. The share of Japan's HT2 products was the highest at $9.35 \%$. The share of China's HT2 exports was $7.93 \%$ and the second highest and the share of Thailand was $0.7 \%$ which was the lowest in the five countries.

Table 6. Compared with Canada, Mexico, Japan and Germany in 2008

\begin{tabular}{|c|c|c|c|c|c|c|}
\hline & 2008 & China & Canada & Mexico & Japan & Germany \\
\hline PM & & 3.37 & 37.01 & 7.14 & 1.3 & 5.45 \\
\hline \multicolumn{7}{|l|}{ RB } \\
\hline & RB1 & 14.02 & 36.30 & 3.69 & 6.14 & 4.25 \\
\hline & $\mathrm{RB} 2$ & 7.29 & 8.58 & 2.85 & 4.14 & 6.24 \\
\hline \multicolumn{7}{|l|}{ LT } \\
\hline & $\begin{array}{l}\text { L11 } \\
\text { LT2 }\end{array}$ & $\begin{array}{l}28.02 \\
27.32\end{array}$ & $\begin{array}{r}2.19 \\
11.72\end{array}$ & $\begin{array}{l}5.13 \\
9.29\end{array}$ & $\begin{array}{l}0.41 \\
3.62\end{array}$ & $\begin{array}{l}0.62 \\
3.08\end{array}$ \\
\hline \multicolumn{7}{|l|}{ MT } \\
\hline & MT1 & 3.11 & 24.48 & 16.86 & 26.75 & 13.56 \\
\hline & MT2 & 13.56 & 19.07 & 7.56 & 6.75 & 5.46 \\
\hline UT & MT3 & 13.32 & 10.94 & 17.75 & 11.50 & 10.66 \\
\hline 111 & HT1 & 27.20 & 4.42 & 19.31 & 7.00 & 3.00 \\
\hline & HT2 & 7.93 & 13.77 & 5.86 & 9.35 & 16.15 \\
\hline
\end{tabular}

Source: Figures are calculated using the data provided by the UN Comtrade database 
Table 7. Compared with korea, thailand, malaysia and japan in 2008

\begin{tabular}{|c|c|c|c|c|c|c|}
\hline & 2008 & China & Korea & Thailand & Malaysia & Japan \\
\hline PM & & 3.37 & 00.53 & 0.10 & 0.26 & 1.30 \\
\hline \multicolumn{7}{|l|}{ RB } \\
\hline & RB1 & 14.02 & 03.38 & 1.92 & 0.58 & 6.14 \\
\hline & RB2 & 7.29 & 01.24 & 0.37 & 0.04 & 4.14 \\
\hline \multicolumn{7}{|l|}{ LT } \\
\hline & LT1 & 28.02 & 0.94 & 1.85 & 1.13 & 00.41 \\
\hline & LT2 & 27.32 & 01.82 & 1.36 & 0.63 & 03.62 \\
\hline \multicolumn{7}{|l|}{ MT } \\
\hline & MT1 & 3.11 & 5.13 & 0.18 & 0.02 & 26.75 \\
\hline & MT2 & 13.56 & 2.89 & 0.45 & 0.69 & 6.75 \\
\hline & MT3 & 13.32 & 02.85 & 1.04 & 1.25 & 11.50 \\
\hline \multicolumn{7}{|l|}{ HT } \\
\hline & HT1 & 27.20 & 04.42 & 19.31 & 4.07 & 7.00 \\
\hline & HT2 & 07.93 & 13.77 & 05.86 & 1.45 & 9.35 \\
\hline
\end{tabular}

Table 8. The change of trade structure for different categories of manufactures

\begin{tabular}{llllll}
\hline $2004 \sim 2008$ & PB & RB & LT & MT & HT \\
\hline Structural Change Index & 0.121 & 0.122 & 0.127 & 0.194 & 0.095 \\
Structural Optimization Index & 0.026 & 0.001 & 0.117 & 0.112 & 0.087 \\
\hline
\end{tabular}

Source: Figures are calculated using the data provided by the UN Comtrade database

In summary, we can see: (1) In contrast to three other BRIC countries, apart from PM products, all the other Chinese manufactured export have an absolute advantage in the US import market, far above the total share of the other three countries. (2) Compared with Canada, Mexico, Japan and Germany, the only overwhelming advantage that China has is in LT and HT1 products and the rest remaining are of no obvious advantage. (3) In comparison with other Asian countries, with the exception of MT1 and HT2 products, China has conspicuous advantage in all the other products. Moreover, the overall advantage of Korea exceeds Thailand and Malaysia in the US market.

\subsection{The Measurement of Trade Structural Change Index}

There are two indexes measuring trade structural change, the Lawrence Index (also called Structural Change Index) and the Beneficiary Index (also called Structural Optimization Index). The Lawrence Index varies from zero to one. The higher the index is, the more obviously trade structure changes. The Beneficiary Index reflects whether a country's export structure changes corresponding with the world dynamic demand. That is to say, it measures the optimization scope of a country's structure. If the figure is positive, it indicates that the export structure tends to be optimized. The bigger the figure, the more obviously the trade structure is optimized.

Table 8 shows the Structural Change Index and Structural Optimization Index for the categories of manufactures over 2004-08, whose result indicates: (1) The Optimization Indexes of all types of manufactures were above zero, illustrating that the Chinese manufactures export structure tended to be optimized. (2) In terms of Change Indexes for categories of manufactures, the most obvious one was MT products, while the least was HT products, where the Change Indexes for PM products were similar to that of RB and LT products. The Structural Optimization Indexes of LT, MT and HT products were positively correlated to their Structural Change Indexes, indicating that their structural changes correspond with the world demand tendencies. Instead, although there are great structural changes for PM and $\mathrm{RB}$ products and the optimization scope is narrow.

\section{CONCLUSION}

\subsection{Conclusions and Implications}

Over 1999-2009, whether in the world market or the US market, the once dominant position in Chinese manufactured exports for LT products was gradually replaced by HT products, the share of HT products in the total Chinese exports was about $35 \%$ in both markets. The rapid growth of HT products mainly came from the growth of HT1 products (electronic and electrical products).

Over 1999-2009, the trade structure of Chinese manufactured exports to the world caused qualitative change, characterized by the decline of LT product 
shares, the increase in shares of HT products and a slight rise in the share of MT products. In 1999, LT products occupied almost $50 \%$ of China's total exports, being the top export commodity. In 2005, HT products exceeded LT products to become the top export commodity. It remains the top export commodity and accounted for $38 \%$ of China's total exports in 2009 .

Over 1999-2009, the trade structure of Chinese exports to the US caused qualitative change as well. This change was characterized by the decline in shares of LT products and the increase in shares of HT products. As a result, HT products were the top export commodity in 2007 and 2009. All the above closely resemble world export structure.

In the US market, over the period 2004-09, the share of Chinese LT products in the US import market had an extraordinarily conspicuous growth with obvious increases in RB1, MT3 and HT1 products. In contrast to three other BRIC countries, apart from PM products, all the other Chinese manufactured exports had absolute advantage in the US import market, far above the total share of the other three countries combined. Compared with Canada, Mexico, Japan and Germany, the only overwhelming advantage that China had was in LT and HT1 products. The rest remaining were of no obvious advantage. In comparison with other Asian countries, with the exception of MT1 and HT2 products, China had conspicuous advantage in all the other products.

Over 2004-08, the export structure for Chinese manufactured exports continued to optimize. The most obvious example was MT products, while the least was HT products, where the Change Indexes for PM products are similar to that of RB products and LT products.

\subsection{Implications}

For the developing countries that have participated in globalization and international division of labor, the implementation of an export-oriented strategy is a major way to promote the economic development. It is generally believed that the export commodity structure of an exporting country marks its international standing and volume of its trade benefit. Therefore, to enhance the competitiveness of the export commodities and to optimize the export commodity structure has been the goal that various countries are pursuing. China has been a good example. Since the reform and opening-up, export, especially the processing trade, has become the engine of the Chinese economic development. The export commodity structure has transformed from a labor-intensive and resource-intensive structure to a capital-intensive and tech-intensive one, which is confirmed by the result of this study. That is, the hightech products has replaced the low-tech products on the top of the list of the export products of China. However, it needs to be taken into further and deeper analysis, since this change of the Chinese export commodity structure took place under the backdrop of the change of international division. The international division has shifted from the stage of inter-industry division and intra-industry division to the stage of intra-product division. Each change in terms of international division will lead to the reallocation of industries among various countries and regions and the way of each individual country participating in the international division of labor will change as well.

Under the context of intra-product division, multinational corporations have implemented global strategies to allocate resources in different countries. That is, to conduct manufacturing of a certain stage in the country with the greatest advantage for that stage and then process or assemble all the spare parts or the semifinished products at a certain place. Therefore, the elements of products from the processing and assembling countries and regions are no longer pure elements of the export countries and the export products have become the "world products" manufactured by various countries, while the export countries have only functioned in the stage of processing and assembling in the whole procedure, with the research and development and the manufacturing of the components conducted in other countries and regions. China is a typical example. This also explains why China is a "world processing and assembling factory" but not a "world factory". China has been at the lowest point of the Smile Curve, due to the fact that in the whole process of manufacturing, China mostly does processing and assembling.

Under these circumstances, if intra-product division is ignored, the nominal export structure, defined as the share of the high-tech products in the total exports, will be larger and it will not be able to reflect the real export structure of China. It is the nominal exportstructure that we compute in this study. We think the real export structure of China is lower than the nominal export structure. Take the iPhone as an example. China only does the assembling of the components, the core part of which are all imported from the US, Japan, Germany, South Korea and some other countries. From the perspective of added value, the unit wholesale price of iPhone is US\$178.97, with $34 \%$ from Japan, 17\% from South Korea, 6\% from the US, $27 \%$ from other countries and only $3.6 \%$ from China. In 2009, China exported 11.3 million iPhone handsets to the US, earning US\$ 2.023 billion as the nominal export volume. However, from the perspective 
of added value, the export volume of China to the US was only US\$ 73.45 million (Xing and Detert, 2010).

After the financial crisis, there is a necessity for China to strengthen the comparative advantages of the export products and optimize the export structure to stabilize the oversea market demand and secure the export. The target of which is to reduce the external impacts on the Chinese economy, to stabilize and enlarge the domestic employment and to earn and increase the trade profits of China. To achieve all these, the Chinese government has no alternative but to pay close attention to the development of export of the low-tech products and the high-tech products. The reasons are as follows:

From the perspective of the current export structure of China, the high-tech products takes the largest percentage among all the export products of China. However, a large part of the components of these products are manufactured overseas. Even though some of the high-tech products of Chinese exports have the evidence of processing trade and the contributed trade benefits is not high, there is no denying that at least the exports of the high-tech products can alleviate the employment pressure in China. It can be seen that the key to securing the export and the sustainable development of the Chinese economy is to keep the steady export of the high-tech products. To achieve this goal, there is the need to improve the contribution to the production of the high-tech products and to enhance the comparative advantages of these products. Meanwhile, the general technology level of China, the quality of the employed population, the innovativeness of the enterprises and the capacity of the domestic enterprises to provide what is needed by the market are all to be improved and the proportion of the imported production factors in the export commodities is to be reduced.

After several decades of development, there have been great changes in the export of low-tech products. The export volume has increased, the number of the commodities with comparative advantages has gone up and the level of the comparative advantages and the degree of localization has been higher. All these have strengthened the advantages of the commodities in the market and brought in higher added value, which have led to the more stable export of the low-tech products, higher trade benefits and a better employment situation. Therefore, the stable export of the low-tech products is important in order to secure the overseas demand and export. Meanwhile, from the perspective of value chain, the low-tech products do not necessarily mean that the whole producing process is of low-tech content, but part of it or even the core procedure could be technology- intensive. It can be concluded here that China should transform and upgrade the export of the low-tech products to high and new tech industries to achieve industrialization, which will further enhance the comparative advantage and technological contents of the low-tech products.

China should attach great importance to the development and export of the high-tech products, improve its comparative advantage and the contribution to the production of products, to accelerate the transformation and upgrading of the low-tech products and to improve the comparative advantage and technological contents of the low-tech products. This will all work together to optimize the export structure of China and improve the comparative advantage of Chinese exports. This is the fundamental measure to stabilize the overseas market demand and secure export and to keep the sustainable development of the Chinese economy and it is also a necessity for China to transform from a trade power to a great power of trade in the world.

\section{REFERENCES}

Bender, S. and K.W. Li, 2002. The Changing Trade and Revealed Comparative Advantages of Asian and Latin American Manufacture Exports. Economic. University of Sao Paulo.

Chen, Y.M., 2006. Recent advances in FCC technology. Powder Technol., 163: 2-8. DOI: 10.1016/j.powtec.2006.01.001

Cui, L. and M.H. Syed, 2007. The Shifting Structure of China's Trade and Production. 1st Edn., International Monetary Fund, pp: 29.

Gang, F., C.H. Kwan and Y. Zhizhong, 2006. Analyzing the Foreign trade structure based on technologies of traded goods. Econ. Res. J.

Hao, W., M. Risheng and Z. Erzhen, 2005. The Comparative Advantage of Manufacturing Product Export and Trade Structure in China. World Econ.

Kwan, C.H., 2002. Research on the strength of made-inChina from the US market-focusing on IT products. Int. Econ. Rev., 5-12.

Lall, S., 2001. Competitiveness, Technology and Skills. 1 st Edn., Edward Elgar, Cheltenham, ISBN-10: 1840645865, pp: 528.

Lall, S., 2002. The impact of the competition on Asia from China's export of manufactured products. Nankai Econ. Stud.

Schott, P.K., 2008. The relative sophistication of Chinese exports. Econ. Policy, 23: 5-49. DOI: 10.1111/j.1468-0327.2007.00195.x

Xing, Y. and N.C. Detert, 2010. How the iPhone Widens the United States Trade Deficit with the People's Republic of China. SusDev Solutions Private Ltd. 